Available online on 15.01.2018 at http://ujpr.org
Universal Journal of Pharmaceutical Research
An International Peer Reviewed Journal
Open access to Pharmaceutical research
This is an open access article distributed under the terms of the Creative Commons Attribution-Non
Commercial Share Alike 4.0 License which permits unrestricted non commercial use,
provided the original work is properly cited
Volume 2, Issue 6, 2017

\title{
EPIDEMICITY OF VIBRIO CHOLERA IN SANA'A CITY, YEMEN: PREVALENCE AND POTENTIAL DETERMINANTS
}

Ali Abdulkarim Sheiban ${ }^{1}\left(\mathbb{D}\right.$, Hassan A. Al-Shamahy ${ }^{2}$, Nashwan M. Alattab ${ }^{3}{ }^{\mathbb{D}}$, Al-Kasem M. A. Abbas ${ }^{4}$

${ }^{I}$ Department of Medicine, Faculty of Medicine and Health Sciences, Sana' a University, Republic of Yemen.

${ }^{2}$ Medical Microbiology and Clinical Immunology, Faculty of Medicine and Health Sciences, Sana' a University.

${ }^{3}$ Ministary of health and Population, Sana'a city, Republic of Yemen.

${ }^{4}$ Department of Maxillo-Facial Surgery, Faculty of Dentistry, Sana'a University, Republic of Yemen.

\section{ABSTRACT}

Objectives: In 2017, a total of 889854 suspected cholera cases with 2578 deaths were reported from Yemen, thus WHO considered these figures to be the worst epidemic of cholera in recent history of humanity. The aims of the study were to determine the prevalence of Vibrio cholera and protozoa causes in severe diarrhea patients and the potential risk factors of the contracting Vibrio cholera.

Methods: Hospital-based diarrhoeal disease surveillance has been done for 12 days in Bany-alharth district of Sana'a city, where all patients admitted with severe diarrhoea in all health centers in the area were enrolled and tested for Vibrio cholerae, and others causes. The study was conducted on 345 patients and demographic, clinical, and potential risk factors were collected, then stool specimens were collected and processed by standard methods.

Results: The prevalence of $V$. cholerae was $8.1 \%$, intestinal Entamoeba histolytica was $50.7 \%$, and Giardia lamblia was $6.7 \%$ and one case of EPEC while $42 \%$ of diarrheal cases were undiagnosed. There was slightly increasing in the rate of $V$. cholerae infection with increasing age $(15 \%)$. Also there were significant risk factors of dispose sewages to surround environment $(\mathrm{OR}=3.4$ times, $P=0.02)$ and reused Jerry can bottles for drinking water $(\mathrm{OR}=3.1, P=0.03)$ with $V$. cholerae infection Vibrio cholera infection rate and intestinal protozoa infection rates were significantly high.

Conclusion: The findings emphasize that there is cholera epidemic in Sana' city and diarrheal epidemic due to various diagnosed and non diagnosed pathogenic microorganisms which may predispose population of the study to significant health risks. Keywords: Cholera; diarrhoea; prevalence; risk factors, Sana'a city, Saudi Aggression, Yemen.

Article Info: Received 2 November 2017; Revised 8 December; Accepted 31 December, Available online 15 January 2018 口ify Cite this article-



Sheiban AA, Al-Shamahy HA, Alattab NM, Al-Kasem MAA. Epidemicity of vibrio cholera in sana'a city, Yemen: prevalence and potential determinants. Universal Journal of Pharmaceutical Research 2017; 2(6): 1-5.

DOI: http://doi.org/10.22270/ujpr.v2i6.R1

Address for Correspondence

Prof. Hassan A. Al-Shamahy, Faculty of Medicine and Heath Sciences, Sana'a University, P.O. Box 775 Sana'a, Yemen,Tel: +967-1-239551,Mobile: +967-770299847, E-mail: shmahe@yemen.net.ye

\section{INTRODUCTION}

Cholera occurs following infection of the intestine by the $\mathrm{O} 1$ or $\mathrm{O} 139$ sero-groups of the bacterium Vibrio

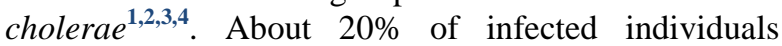
develop acute, watery diarrhoea and $10-20 \%$ of these progress severe watery diarrhoea ${ }^{5}$. Even though casefatality rates have dropped due to oral and intravenous rehydration therapy, cholera can cause severe disease because of its rapid onset; residents in low-income locations as Yemen are at particularly high risk of infection in areas where public health systems cannot cope with outbreaks as in Yemen in which about $60 \%$ of public health system have been destroyed by the Saudi aggression on Yemen for 3 years and still continue ${ }^{6}$. In 2017, a total of 889854 suspected cholera cases were reported from Yemen, including 2578 deaths, to the World Health Organization (WHO) ${ }^{6,7}$.
So WHO considered these figures to be worst epidemic of cholera in recent history of humanity. As the fact that the WHO considered reported figures from endemic areas of cholera are underestimates, as poor surveillance systems and fear of negative impact on trade and tourism in many countries likely led to underreporting ${ }^{7,8}$. WHO estimates that officially reported cases represent only $5-10 \%$ of the actual number occurring worldwide annually ${ }^{6}$. Cholera is an endemic in Yemen ${ }^{9}$. In Yemen, cholera occurs year-round with seasonal peaks typically before and after rainy seasons with limited number of cases ${ }^{9}$. The true burden of cholera is unknown in Yemen due to the lack of a population-based surveillance system. The estimation of cholera prevalence is particularly important to take effective control measures, including the provision of clean water, improved hygiene and sanitation, and 
introduction of cholera vaccines. Oral cholera vaccines have been found to be safe and effective $\mathrm{e}^{10,11,12}$. However, modeling studies have shown that water and sanitation measures may provide an equally viable solution, especially in the long term, since the immunization granted by vaccines wanes over time $^{13,14,15}$. Two types of inactivated cholera vaccines are currently available: one containing recombinant cholera toxin B subunit and killed cholera whole cells (rBS-WC) and the other containing only killed cholera whole cells (WC) ${ }^{16,17}$. Field trials demonstrated that both vaccines provided $>50 \%$ protection for $3 \mathrm{yrs}^{16,18}$. However, the WC vaccine is cheaper, at US\$1.85 per dose in the public sector, with a protective efficacy of $66 \%$ during the third year of follow-up, as reported in a recent study from Kolkata, India ${ }^{19}$. Credible data regarding incidence of cholera is currently unavailable in Yemen, which limits the validity of any costeffectiveness evaluation of a potential intervention programme. The aims of the study were to determine the prevalence of Vibrio cholera and protozoa causes among Yemeni patients suffering from severe diarrhea and the potential risk factors of the contracting Vibrio cholera.

\section{MATERIALS AND METHODS Case definition}

We defined severe diarrhoea as frequent loose or liquid stools for which a person had to be admitted to a healthcare facility, or had to receive intravenous rehydration, or had died as a result of the diarrhoeal illness.

\section{Data collection}

Data including demographic data of the patients, clinical information, and potential risk factors as water sources, food ingestion, sewage discarding, etc. time of disease, time of collection the specimen, etc. The findings were recorded in a form with laboratory results.

\section{Laboratory testing}

Following rectal swab or stool specimens collection, samples were immediately placed in Cary-Blair transport media. All samples were cultured in the AlThorah hospital microbiology laboratory using standard bacteriological methods ${ }^{20,21}$. In the laboratory, the rectal swabs or stool specimens were incubated in alkaline peptone water (APW) at $37^{\circ} \mathrm{C}$ for $4 \mathrm{~h}$. The rectal swabs or stool specimens, as well as the 4-h broth enrichments, were inoculated by streaking on taurocholate-tellurite-gelatin agar (TTGA). Colonies resembling $V$. cholerae were agglutinated with antisera specific for $V$. cholerae $\mathrm{O} 1$ and $V$. cholerae $0139^{21}$.

\section{Sample size}

We calculated the sample size for healthcare utilization survey in the catchment area of surveillance hospitals by using the sample size calculation, it was assumed that in the catchment area of Sana'a city-based surveillance health centers and hospitals there would be about 800000 severe diarrhoea patients per year. With expected frequency of cholera among them equal to $8.1 \%$, and with acceptable margin of error $2.9 \%$, with design effect 1 and for one cluster, we need at least 340 severe diarrhoeal cases in $95 \%$ confidence level.

Cholera case definitions and data analysis

All patients with positive colonies of $V$. cholerae and agglutinated with antisera specific for $V$. cholerae $\mathrm{O} 1$ and $V$. cholerae $\mathrm{O} 139$ were considered to have had cholera infection. To relate possible risk factors for cholera infection, the data were examined in a casecontrol study format. For severe diarrhoeal cases with evidence of infection with $V$. cholerae were matched up with those who were $V$. cholerae negative. Differences in categorical variables were assessed using Fisher's exact tests where appropriate. Ninetyfive percent confidence intervals for odds ratios were calculated according to the method of Cornfield and 95\% confidence limits for simple proportions were calculated by an exact binomial method using EPIINFO.

\section{Ethical approval}

The field team obtained written consent from the identified severe diarrhoeal cases or their guardians. Assent was taken from participants aged between 11 and 17 years. In the surveillance hospitals, consent was also obtained from patients with diarrhoea before collecting the stool specimen. The study protocol was reviewed and approved by the Ethics Committee of Sana'a University, Faculty of Medicine and Health Sciences.

Table 1: Age distribution of the patients suffering from severe diarrhoea that tested for $V$. cholerae infection positivity in Sana'a cityYemen, (July 2017).

\begin{tabular}{ccc}
\hline \multirow{2}{*}{ Age groups } & \multicolumn{2}{c}{ Total } \\
\cline { 2 - 3 }$(\mathbf{n = 3 4 5})$ \\
\hline No. & $\mathbf{\%}$ \\
\hline $5-10$ years & 165 & 47.8 \\
\hline $11-20$ years & 149 & 43.1 \\
\hline$\geq 21$ years & 27 & 7.8 \\
\hline
\end{tabular}

\section{RESULTS}

The study includes 345 patients of sever diarrhoea in Sana'a city during a period of 12 days, starting in July $1^{\text {st }} 2017$ and ending in July 12th 2017. The tested patients ages were ranged from 1 years to 65 years old, most of individuals were in age groups of $<5$ years $(47.8 \%)$, followed by age group 5-10 years $(43.1 \%)$, while only $7.8 \%$ of the total were in age group 11-20 years and only $1.5 \%$ were in age group $\geq$ 21 years (Table 1). The prevalence of $V$. cholerae was $8.1 \%, 3.5 \%$ of them as single cause and $4.6 \%$ were suffering from co-infection of $V$. cholerae (4.4\% with E. histolytica). The prevalence of intestinal Entamoeba histolytica was $50.7 \%$, in which $40.9 \%$ of them as single cause and $9.9 \%$ were suffering from co-infection with other micro-organisms. The prevalence of intestinal G. lamblia was $6.7 \%$, in which $2.6 \%$ of them as single cause and $4.1 \%$ were suffering from coinfection. However, a low prevalence of EPEC $(0.6 \%)$ and $H$. nana $(2 \%)$ were very low. 
Table 2: The frequency of different bacterial, protozoa and parasites that diagnosed among The patients suffering from severe diarrhoea whom tested for $V$. cholerae infection in Sana'a city-Yemen, (July 2017).

\begin{tabular}{|c|c|c|}
\hline \multirow[t]{2}{*}{ Agents } & \multicolumn{2}{|c|}{ Frequency } \\
\hline & Number & Percentage \\
\hline V. cholerae & $28 / 345$ & 8.1 \\
\hline Single & $12 / 345$ & 3.5 \\
\hline infection & $16 / 345$ & 4.6 \\
\hline \multicolumn{3}{|l|}{ Co-infection } \\
\hline Entamoeba & $175 / 345$ & 50.7 \\
\hline histolytica & $141 / 345$ & 40.9 \\
\hline Single & $34 / 345$ & 9.9 \\
\hline \multirow{2}{*}{\multicolumn{3}{|c|}{$\begin{array}{l}\text { infection } \\
\text { Co-infection }\end{array}$}} \\
\hline & & \\
\hline Giardia & $23 / 345$ & 6.7 \\
\hline lamblia & $9 / 345$ & 2.6 \\
\hline Single & $14 / 345$ & 4.1 \\
\hline \multirow{2}{*}{\multicolumn{3}{|c|}{$\begin{array}{l}\text { infection } \\
\text { Co-infection }\end{array}$}} \\
\hline & & \\
\hline H. nana & $7 / 345$ & 2 \\
\hline Single & $3 / 345$ & 0.9 \\
\hline infection & $4 / 345$ & 1.2 \\
\hline \multicolumn{3}{|l|}{ Co-infection } \\
\hline$E P E C$ & $2 / 345$ & 0.6 \\
\hline Single & $2 / 345$ & 0.6 \\
\hline infection & $0 / 345$ & \\
\hline \multicolumn{3}{|l|}{ Co-infection } \\
\hline Undiagnosed & $145 / 345$ & 42 \\
\hline $\begin{array}{l}\text { Total } \\
\text { diagnosed }\end{array}$ & $200 / 345$ & 58 \\
\hline
\end{tabular}

Table 3: The association between $V$. cholerae infections and the age groups of the patients suffering from severe diarrhoea in Sana'a city-Yemen, (July 2017).

\begin{tabular}{|c|c|c|c|c|c|c|}
\hline \multirow[t]{2}{*}{ Age groups } & \multicolumn{2}{|c|}{$\begin{array}{c}V . \text { cholerae } \\
\text { positive culture } \\
(\mathrm{n}=28)\end{array}$} & \multirow[t]{2}{*}{ OR } & \multirow[t]{2}{*}{ CI } & \multirow[t]{2}{*}{$\chi^{2}$} & \multirow[t]{2}{*}{$\boldsymbol{P}$} \\
\hline & No. & $\%$ & & & & \\
\hline$<5$ years $n=162$ & 10 & 6.2 & 0.6 & $0.26-1.3$ & 1.5 & 0.21 \\
\hline $5-10$ years $n=149$ & 14 & 9.4 & 1.3 & $0.1-2.9$ & 0.57 & 0.44 \\
\hline $11-20$ years $n=27$ & 4 & 15 & 2.1 & $0.7-6.6$ & 1.7 & 0.18 \\
\hline$\geq 21$ years $n=5$ & 0 & 0 & \multirow{2}{*}{\multicolumn{4}{|c|}{ undefined }} \\
\hline $\begin{array}{l}\text { Crude rate } \\
\mathrm{N}=345\end{array}$ & 28 & 8.1 & & & & \\
\hline
\end{tabular}

OR- odds ratio $=>1$ (risk), CI- Confidence intervals 1 to more than $1, \mathrm{X}^{2}$ - Chi-square $=>3.9$ ( significant), $P$-Probability value $=<0.05$ (significant)

On other hand $42 \%$ of diarrheal cases were undiagnosed (unknown causes) (Table 2). There was slightly increasing in the rate of $V$. cholerae infection with increasing age, in which the highest rate occurred in age group 11-20 years old (15\%), followed by $5-10$ years old $(9.4 \%)$, while the rates in age group $<5$ years old was $6.2 \%$, and in $\geq 21$ years were zero $\%$ (Table 4 ). When the sources of drinking water versus $V$. cholerae infection were considered, there was a highly significant increasing in the rate of $V$. cholerae infection with Jerry can bottles using $(16.1 \%$, with $\mathrm{OR}=3.1$ times, $\mathrm{CI}=1.5-6.9$, and $P=0.02$ ). However, there was no significant association between $V$. cholerae infections and other sources of drinking water (Table 4). There was a highly significant increasing in the rate of $V$. cholerae infection with dispose sewages to the house surround environment (rate $=21 \%$, with $\mathrm{OR}=3.4$ times, $\mathrm{CI}=1.1-10.9$ times, $P=0.03)$. However, there was protective level of government sewage system against $V$. cholerae infections (Table 5).

\section{DISCUSSION}

This study provides data on prevalence and potential risk factors of cholera among severe diarrhoea in Sana'a city in Yemen which will be useful to inform decisions for effective control measures. The study results show variability in rates at different age groups, in which there was slightly increasing in the rate of $V$. cholerae infection with increasing age (Table 4). Current study results is similar to that observed in Bangladesh that children cholera more frequently in older children compared to young children during diarrhoeal illness ${ }^{4}$. Higher rate of cholera in older patients might be related to those older children exposed to risk factors that related to out-door activities. When the sources of drinking water versus $V$. cholerae infection were considered, there was a highly significant increasing in the rate of $V$. cholerae infection with Jerry can bottles using $(16.1 \%$, with $O R=3.1$ times, $C I=1.5-6.9$, and $P=0.02$ ) (Table 4). Higher rate of cholera with Jerry can bottles using might be related to faecal contamination of drinking 
water sources or faecal contamination of the re-used jerry can bottles.

There was a highly significant increasing in the rate of $V$. cholerae infection with dispose sewages to the house surround environment (rate $=21 \%$, with $O R=3.4$ times, $\mathrm{CI}=1.1-10.9$ times, $P=0.03$ ) (Table 5).This risk might be related to faecal contamination of drinking water. Bany Al-Harath distract is a densely populated area and has one of the largest concentrations of slums in Sana'a city. Slum settlements often have unhygienic latrines, poor garbage management systems, and sewers that overflow into houses. In most cases, latrines are linked with sewerage lines and municipal water pipes are commonly exposed to sewerage lines which may lead to faecal contamination of the supply water source.

Table 4: The association between $V$. cholerae infections and the sources of drinking water for the patients suffering from severe diarrhoea in Sana'a city-Yemen, (July 2017).

\begin{tabular}{|c|c|c|c|c|c|c|}
\hline \multirow[t]{2}{*}{ Water sources } & \multicolumn{2}{|c|}{$\begin{array}{c}\text {. cholerae } \\
\text { positive culture } \\
(\mathrm{n}=\mathbf{2 8})\end{array}$} & \multirow[t]{2}{*}{ OR } & \multirow[t]{2}{*}{ CI } & \multirow[t]{2}{*}{$\chi^{2}$} & \multirow[t]{2}{*}{$P v$} \\
\hline & No. & $\%$ & & & & \\
\hline Water pump $\mathrm{n}=75(21.7 \%)$ & 3 & 4 & 0.4 & $0.11-1.3$ & 2.1 & 0.14 \\
\hline Hand well $n=2(0.6 \%)$ & 0 & 0 & & & & \\
\hline Water grid $n=5(1.4 \%)$ & 1 & 20 & 2.9 & $0.3-26$ & 0.96 & 0.32 \\
\hline Stream $n=1(0.3 \%)$ & 0 & 0 & & & & \\
\hline Commercial containers $n=131(38 \%)$ & 10 & 7.6 & 0.8 & $0.4-2$ & 0.06 & 0.7 \\
\hline Mineral water $n=11(3.2 \%)$ & 1 & 9.1 & 1.1 & $0.4-9.2$ & 0.01 & 0.9 \\
\hline Reused Jerry can bottles $n=81(23.5 \%)$ & 13 & 16.1 & 3.1 & $1.5-6.9$ & 8.9 & 0.02 \\
\hline $\begin{array}{l}\text { Crude rate } \\
\mathrm{N}=345\end{array}$ & 28 & 8.1 & & & & \\
\hline
\end{tabular}

Table 5: The association between $V$. cholerae infections and the swages system for the patients suffering from severe diarrhoea in Sana'a city - Yemen, (July 2017).

\begin{tabular}{|c|c|c|c|c|c|c|}
\hline \multirow[t]{2}{*}{ Swages } & \multicolumn{2}{|c|}{$\begin{array}{c}V . \text { cholerae } \\
\text { positive culture } \\
(n=28)\end{array}$} & \multirow[t]{2}{*}{ OR } & \multirow[t]{2}{*}{ CI } & \multirow[t]{2}{*}{$\chi^{2}$} & \multirow[t]{2}{*}{$P v$} \\
\hline & No. & $\%$ & & & & \\
\hline Doge hole $n=244(70.7 \%)$ & 20 & 8.2 & 1.0 & $0.44-2.4$ & 0.007 & 0.93 \\
\hline Government sewage $n=73(21.2 \%)$ & 4 & 5.5 & 0.6 & $0.2-1.7$ & 0.86 & 0.35 \\
\hline Dispose to surround environment $\mathrm{n}=19(5.5 \%)$ & 4 & 21 & 3.4 & $1.1-10.9$ & 4.5 & 0.03 \\
\hline Crude rate $\mathrm{N}=345$ & 28 & 8.1 & & & & \\
\hline
\end{tabular}

In this study, the prevalence of intestinal Entamoeba histolytica was $50.7 \%$, in which $40.9 \%$ of them as single cause and $9.9 \%$ were suffering from co-infection with other micro-organisms, current study results were similar compared to previous studies done at Libya and others African countries in which intestinal Entamoeba histolytica was the most common cause of diarrhea among children ${ }^{22,23}$. High prevalence of intestinal Entamoeba histolytica is attributed by poor personal hygienic practices and poor environmental sanitation. Also E. histolytica and G. lamblia can directly transmit through food-handlers to consumers if ingested via contaminated food and water because cysts do not need environmental maturation ${ }^{24,25}$. Finally, for the confirmation of cholera cases, this study used a conventional culture method which remains the gold standard, but this procedure may yield false-negative results in case of inactivation of $V$. cholerae by in-vivo vibriolytic action of the phage and/or non-cultivability induced as a result of host response ${ }^{26,27,28}$. Rapid antigen-based diagnostic tests for cholera dipstick assays have identified $0-32 \%$ more cases than the conventional culture method in detecting $V$. cholerae antigens in stool samples ${ }^{26,29,30,31}$. By not accounting for culture-negative $V$. cholerae cases we are underestimating total cholera prevalence, but we did not adjust the prevalence calculations for culture negatives because we did not have molecular evidence from this population to estimate the magnitude of the correction.

\section{CONCLUSION}

Vibrio cholera infection rate, and intestinal protozoa infection rates were significantly high. The findings emphasize that there is cholera epidemic in Sana' city and diarrheal epidemic due to various diagnosed and non diagnosed pathogenic microorganisms which may predispose population of the study to significant health risks. Therefore, constant epidemiological surveillance and applying proper preventive measures through biannual routine parasitological tests and treatment of the infected cases along with the improvement of environmental sanitation are recommended.

\section{ACKNOWLEDGEMENTS}

Authors acknowledge the financial support of MHP, Sana'a Yemen, and WHO Sana'a office. 


\section{AUTHOR'S CONTRIBUTION}

The manuscript was carried out, written, and approved in collaboration with all authors.

\section{CONFLICT OF INTEREST}

No conflict of interest associated with this work.

\section{REFERENCES}

1. Snow J. On the mode of communication of cholera, 1855. Salud publica de Mexico 1991; 33:194-201.PMID: 2053025

2. Sack DA, et al. Cholera. Lancet 2004; 363:223-233. https://doi.org/10.1016/S0140-6736(12)60436-X

3. Nair GB, et al. Spread of Vibrio cholerae O139 Bengal in India. J Infect Dis 1994; 169:1029-1034. https://doi.org/10.1093/infdis/169.5.1029

4. Paul RC, Faruque ASG, Alam M et al. Incidence of severe diarrhoea due to Vibrio cholevae in the catchment area of six surveillance hospitals in Bangladesh. Epidemiol Infect 2016; 144(5): 927-939. https://doi.org/10.1017/S0950268815002174

5. World Health Organization. Cholera outbreak: assessing the outbreak response and improving preparedness: Global Task Force on Cholera Control; 2004

6. MHP Yemen, Electronic Disease Early Warning System (eDEWS). Weekly Epidemiological Bulletin W46 2017 (Nov 13-Nov 19).https://doi.org/10.5455/aim.2019.27.85-88

7. WHO. Cholera surveillance and number of cases. Geneva: WHO; (Accessed 22 August 2017). (http://www.who.int/topics/cholera/surveillance/en/index html).

8. Kimball AM, Wong KY, Taneda K. An evidence base for international health regulations: quantitative measurement of the impacts of epidemic disease on international trade. Revue Scienti fiqueet Technique (International Office of Epizootics) 2005; 24:825-832.

9. MHP Yemen. Relief Web. Yemen-Cholera outbreak - DG ECHO Daily Map | 23/11/2017

10. Lopez AL, et al. Cholera vaccines for the developing world. Human Vaccines 2008; 4: 165-169.

11. Clemens JD, et al. Field trial of oral cholera vaccines in Bangladesh: results of one year of follow-up. J Infect Dis 1988; 158:60-69. https://doi.org/10.1093/infdis/158.1.60

12. Sur D, et al. Efficacy and safety of a modified killedwhole-cell oral cholera vaccine in India: an interim analysis of a cluster-randomised, double-blind, placebocontrolled trial. Lancet 2009; 374:1694-1702. https://doi.org/10.1016/S0140-6736(09)61297-6

13. Andrews JR, Basu S. Transmission dynamics and control of cholera in Haiti: an epidemic model. Lancet 2011; 377:1248-1255. https://doi.org/10.1016/S0140-6736(11)60273-0

14. Bertuzzo E, et al. Prediction of the spatial evolution and effects of control measures for the unfolding Haiti cholera outbreak. Geophysical Res Let 2011; 38 L06403. https://doi.org/10.1029/2011GL046823

15. Tuite AR, et al. Cholera epidemic in Haiti, 2010: using a transmission model to explain spatial spread of disease and identify optimal control interventions. Annals Internal Med 2011; 154:593-601.
16. WHO. Cholera vaccines. Weekly Epidemiological Record 2011; 76:117-124.

17. Chaignat CL, Monti V. Use of oral cholera vaccine in complex emergencies: what next? Summary report of an expert meeting and recommendations of WHO. J Health Popul Nutrit 2007; 25:244-261. PMID: 17985828

18. Clemens JD, et al. Field trial of oral cholera vaccines in Bangladesh: results from three-year followup. Lancet 1990; 335:270-273. https://doi.org/10.1016/0140-6736(90)90080-O

19. Sur D, et al. Efficacy of a low-cost, inactivated whole-cell oral cholera vaccine: results from 3 years of follow-up of a randomized, controlled trial. PLoS Neglected Trop Dis 2011; 5:e1289. https://doi.org/10.1371/journal.pntd.0001289

20. Alam M, et al. Seasonal cholera caused by Vibrio cholerae sero-groups $\mathrm{O} 1$ and $\mathrm{O} 139$ in the coastal aquatic environment of Bangladesh. Applied Env Microbiol2006; 72:4096-4104.https://doi.org/10.1128/AEM.00066-06

21. WHO. World Health Organization Guidelines for the laboratory diagnosis of cholera. Geneva: WHO Bacterial Disease Unit; 1974 https://doi.org/10.1371/journal.pntd.0003832

22. Ali MB, Ghenghesh KS, Ben Aissa R, Abuhelfaia A, Dufani MA. Etiology of childhood diarrhea in ZlitenLibya. Saudi Med J 2005; 26:1759-65.

23. El Ammari NE, Nair GA. Critical evaluation of the intestinal Protozoan parasites among Libyan and other African residents of Al-Khoms, Libya. J Entomol Zool Stud 2015; 3:42-6.

24. Ghenghesh K S, Ghanghish K, Ben Darif ET, Khaled S, Ezzadin F. Prevalence of Entamoeba histolytica, Giardia lamblia, and Cryptosporidium spp. in Libya: 2000-2015. Libyan J Med 2016; 11: 10. https://doi.org/10.3402/ljm.v11.32088

25. Cheesbrough M. Medical laboratory manual for tropical countries, $2^{\text {nd }}$ ed. Oxford, Butterworth; 1992. https://doi.org/10.1016/0035-9203(82)90237-1

26. Alam M, et al. Diagnostic limitations to accurate diagnosis of cholera. J Clin Microb 2010; 48:3918-3922. https://doi.org/10.1128/JCM.00616-10

27. Colwell RR, et al. Viable but non-culturable Vibrio cholerae $\mathrm{O} 1$ revert to a cultivable state in the human intestine. World J Micro Biotech 1996; 12:28-31. https://doi.org/10.1007/BF00327795

28. Faruque SM, et al. Transmissibility of cholera: in vivoformed biofilms and their relationship to infectivity and persistence in the environment. Proceedings of the National Academy of Sciences USA. 2006; 103:63506355.http://doi.org/10.1073/pnas.0601277103

29. Boncy J, et al. Performance and utility of a rapid diagnostic test for cholera: notes from Haiti. Diagnostic Microbiol Infect Dis2013; 76:521-523. https://doi.org/10.1016/j.diagmicrobio.2013.03.010

30. Ley B, et al. Evaluation of a rapid dipstick (Crystal VC) for the diagnosis of cholera in Zanzibar and a comparison with previous studies. PLoS ONE. 2012; 7:e36930. https://doi.org/10.1371/journal.pone.0036930

31. Nato F, et al. One-step immunochromatographic dipstick tests for rapid detection of Vibrio cholerae $\mathrm{O} 1$ and $\mathrm{O} 139$ in stool samples. Clinical Diag Lab Immunol 2003; 10:476-478. https://doi.org/10.1128/CDLI.10.3.476478.2003 